\title{
Plasma Lipoprotein Induction and Suppression of the Generation of Cellular Procoagulant Activity in Vitro
}

\author{
REQUIREMENTS FOR CELLULAR COLLABORATION
}

\author{
Gary A. Levy, Bradford S. Schwartz, Linda K. CURTiss, and \\ ThOMAS S. EDGington, Department of Molecular Immunology, The Research \\ Institute of Scripps Clinic, La Jolla, California 92037
}

\begin{abstract}
A B S T R A C T Isolated human plasma very low density, intermediate density, and high density lipoproteins at physiologic concentrations have been demonstrated in the preceding report to induce significant increases in the procoagulant activity of human peripheral blood mononuclear cells in vitro, whereas low density lipoprotein did not. The monocyte was identified in this study by cellular fractionation and by direct cytologic assays as the source of this inducible activity, thus identifying the procoagulant activity as a monokine. The generation of these lipoproteininduced procoagulant monokines was entirely dependent upon the presence of lymphocytes. Isolated lymphocytes that had been exposed to the stimulatory lipoproteins could induce monocytes to produce the procoagulant activity, whereas neither the culture medium from lipoprotein-stimulated lymphocytes, homogenates of lymphocytes, nor other cells such as platelets could substitute for this requirement. The interaction of the stimulatory lipoproteins with lymphocytes was rapid, reaching completion within $30 \mathrm{~min}$, and was equally effective at either $4^{\circ}$ or $37^{\circ} \mathrm{C}$. Low density lipoprotein did not stimulate lymphocytes to induce monocyte procoagulant activity, but did actively suppress the production of the procoagulant monokines induced by each of the stimulatory lipoproteins, as well as bacterial lipopolysaccharide. The monocyte was identified as the cell sensitive to low density lipoprotein suppression, and no suppression of lymphocyte triggering was observed. These observations on the interaction of plasma lipoproteins with lymphocytes and monocytes in vitro introduce two new regulatory events by which plasma lipoproteins influence the function of cells, and define a regulatory network by
\end{abstract}

This is Scripps Clinic publication number 2108.

Received for publication 18 September 1980 and in revised form 29 December 1980. which certain lipoprotein classes trigger lymphocytes, which can in turn induce monocytes to express procoagulant activity. Only this latter phase is subject to lipoprotein suppression by physiologic concentrations of low density lipoprotein.

\section{INTRODUCTION}

A marked increase in both the surface expression by viable cells and total content of procoagulant activity (PCA $)^{1}$ by human peripheral blood mononuclear cells (PBM) has been observed upon exposure of these cells in vitro to antigen-antibody complexes (1), allogeneic cells (2), mitogenic lectins (3), bacterial lipopolysaccharides (LPS) $(4,5)$ and proteolytic products of C5 $(6)$. In the preceding study it was observed that certain classes of human plasma lipoproteins can also induce PBM to increase their PCA content or expression. Very low density lipoprotein (VLDL), intermediate density lipoprotein (IDL), and high density lipoprotein (HDL) were each capable of inducing PCA in PBM in vitro. In contrast, low density lipoprotein (LDL) was devoid of such activity.

It was demonstrated that the VLDL-induced PCA was a classical Factor VII-dependent and Factor Xdependent tissue thromboplastin, apparently identical to that induced by LPS and other previously described stimuli. In contrast, most of the IDL-and HDL-induced PCA was independent of Factor X, as well as of Factors IX and VIII of the intrinsic coagulation pathway, and of Factor VII of the extrinsic pathway. This PCA cleaved prothrombin directly in a manner similar to human Factor $\mathrm{Xa}$, and appeared to represent

\footnotetext{
${ }^{1}$ Abbreviations used in this paper: HDL, high density lipoprotein; IDL, intermediate density lipoprotein; LDL, low density lipoprotein; LPS, lipopolysaccharide; PBM, peripheral blood mononuclear cells; PCA, procoagulant activity; VLDL, very low density lipoprotein.
} 
a new inducible cellular prothrombin activator. Whereas LDL was devoid of stimulatory activity for PBM cell-derived PCA, it actively suppressed the generation of PCA by the stimulatory lipoproteins. This inhibition could be achieved with all the stimulatory lipoproteins at molar ratios of LDL to stimulus of $1: 3$ or less.

Direct observation of murine splenic mononuclear cells incubated with LPS has demonstrated that the induced PCA is localized to macrophages, but that direct lymphocyte collaboration is required for amplification of the endogenous basal macrophage PCA content (7). Lymphocytes exposed to LPS induced an increase of PCA associated with viable macrophages as well. This collaboration appeared to require direct cellular contact and was not mediated under these conditions by soluble lymphocyte products (7). In a recent study of human PBM, Edwards et al. (8) have observed that soluble products of phytohemagglutinin-stimulated T lymphocytes induce PCA in human monocyterich cell fractions. In the present study, we explore the collaborative cellular requirements for the generation of plasma lipoprotein-induced, human PBM PCA, a previously unexplored system. In addition, the site of action of LDL-mediated suppression of this cellular PCA is identified.

\section{METHODS}

Lipoproteins. The plasma lipoproteins were isolated by differential centrifugation in $\mathrm{KBr}$ and characterized as described in the accompanying manuscript. The lipoprotein fractions included the VLDL $(d<1.006 \mathrm{~g} / \mathrm{ml})$, IDL $(d=1.006$ $1.019 \mathrm{~g} / \mathrm{ml})$, LDL $(d=1.019-1.063 \mathrm{~g} / \mathrm{ml})$, and HDL $(d$ $=1.063-1.21 \mathrm{~g} / \mathrm{ml}$ ). The preparations were analyzed for protein concentration by a modification (9) of the method of Lowry et al. using a bovine albumin standard and stored sterile at $4^{\circ} \mathrm{C}$ in lipoprotein buffer $(0.15 \mathrm{M} \mathrm{NaCl}, 0.15 \mathrm{mM}$ EDTA, $0.0005 \%$ alpha tocopherol, $\mathrm{pH} 7.4$ ). LPS contamination of the lipoproteins was monitored by both limulus and mouse lethality assays as described $(10,11)$. Endotoxin contamination was undetectable at $<1 \mathrm{ng} / \mathrm{mg}$ of lipoprotein protein.

Cell isolation and culture. PBM were isolated from the blood of fasting healthy donors by centrifugation over ficollhypaque at $1,400 \mathrm{~g}$ and $22^{\circ} \mathrm{C}$ for $12 \mathrm{~min}$ as described (12). The PBM contained an average of $85 \%$ lymphocytes, $12 \%$ monocytes, and $3 \%$ or less polymorphonuclear leukocytes as assessed by cytology, vital uptake of neutral red, and nonspecific esterase stains (13). Platelet contamination of these PBM averaged 37 platelets per PBM. This was reduced to $<0.5$ platelets per PBM by centrifuging the whole blood at $120 \mathrm{~g}$ for $15 \mathrm{~min}$ and removing the platelet-rich plasma before ficoll-hypaque centrifugation. Lymphocytes and monocytes were separated by adherence to plastic in flat bottom, 16-mm Diam, 24-well plates (Costar, Data Packaging, Cambridge, Mass.) in 1-ml volumes in complete medium (RPMI 1640 containing $10 \%$ fetal calf serum, $100 \mathrm{U} / \mathrm{ml}$ penicillin, and $50 \mu \mathrm{g} / \mathrm{ml}$ streptomycin) at $37^{\circ} \mathrm{C}$ and $6 \% \mathrm{CO}_{2}$ for $48-72 \mathrm{~h}$. The lymphocytes were suspended and removed, and the adherent monocyte layer was washed with medium. Monocytes were removed by gentle agitation at $150 \mathrm{rpm}$ on a gyratory platform for $25 \mathrm{~min}$ at $22^{\circ} \mathrm{C}$ in Puck's Saline A (Gibco Labora- tories, Grand Island Biological Co., Grand Island, N. Y.) containing $3 \%$ bovine serum albumin and $3 \mathrm{mM}$ EDTA as previously described (7). All monocyte populations used were $>98 \%$ nonspecific esterase positive and were devoid of platelets, whereas the washed lymphocyte fractions were in all cases $<2 \%$ nonspecific esterase positive.

Platelets were isolated from blood drawn into acid-citrate dextrose. Following centrifugation at $120 \mathrm{~g}$ for $15 \mathrm{~min}$, the platelets were isolated from the platelet-rich plasma by centrifugation at $1,200 \mathrm{~g}$ for $15 \mathrm{~min}$ and washed twice in RPMI 1640. The isolated platelets were contaminated by PBM at $<0.01 \%$.

PBM at $1 \times 10^{6} / \mathrm{ml}$, isolated lymphocytes at $8.5 \times 10^{5} / \mathrm{ml}$, isolated platelets at $2 \times 10^{7} / \mathrm{ml}$, or isolated monocytes at $1-1.5 \times 10^{5} / \mathrm{ml}$ were incubated in complete medium at $37^{\circ} \mathrm{C}$ in $5 \% \mathrm{CO}_{2}$. In some experiments, incomplete medium (no serum) was used. Unless otherwise indicated, the cells were washed twice with RPMI-1640 $6 \mathrm{~h}$ after the addition of test material, and cell viability was assessed by trypan blue exclusion before assay of cellular PCA. Bacterial LPS (Escherichia coli $0111 \mathrm{~B} 4$, butanol extracted) was kindly provided by Dr. David Morrison, Emory University, Atlanta, Ga. and was used as a positive control at a final concentration of $10 \mu \mathrm{g} / \mathrm{ml}$.

PCA. The total cellular content of PCA was quantitated in a one-stage clotting assay (7). Briefly summarized, the washed pellets of PBM, platelets, monocytes or lymphocytes in $12 \times 75-\mathrm{mm}$ polypropylene tubes were frozen at $-70^{\circ} \mathrm{C}$, thawed at $37^{\circ} \mathrm{C}$ three times, and sonicated. The total PCA content was quantitated as follows. To $0.1 \mathrm{ml}$ of cell homogenate in a $12 \times 75-\mathrm{mm}$ glass tube at $37^{\circ} \mathrm{C}$ was added 0.1 $\mathrm{ml}$ of citrated, normal human, platelet-poor plasma. Then, 0.1 $\mathrm{ml}$ of $25 \mathrm{mM} \mathrm{CaCl}$ was added to initiate the reaction. The time (seconds) for the initial appearance of a fibrin clot was recorded. A rabbit brain thromboplastin standard at $36 \mathrm{mg}$ dry mass/ml (Dade, Div. American Hospital Supply, Miami, Fla.) was assigned a value of $100,000 \mathrm{mU}$. Clotting times for 0 and $10,000 \mathrm{mU}$ thromboplastin were 196 and $24 \mathrm{~s}$, respectively. Data are expressed as the mean and standard deviation of replicate assays. Precision of the assay varied from 6.1 to $9.7 \%$ (coefficient of variation). RPMI 1640 with or without $10 \%$ fetal calf serum, buffer, lipoproteins, and LPS were all without activity.

Procoagulant plaque assay. To observe the qualitative presence of PCA in individual cells and to differentiate between monocytes and other cells, suspensions of stimulated and control PBM were air dried onto glass slides (7), fixed in buffered formalin-acetone, and stained for nonspecific esterase $(7,13)$. The fixed cells were overlaid at $39-40^{\circ} \mathrm{C}$ with $0.5 \mathrm{ml}$ of a solution of 3.75 parts $2 \%$ agarose in saline (SeakemAgarose Marine Colloid Division, FMC Corp., Rockland Maine), 1.5 parts Hepes-buffered Eagle's minimum essential medium containing $3.67 \mathrm{~g} \% \mathrm{CaCl}_{2}$ and 1 part platelet-poor, citrated, normal human plasma. After $10 \mathrm{~min}$ at $37^{\circ} \mathrm{C}$, the reaction was terminated by placing the slides in saline containing $10 \mathrm{U}$ heparin $/ \mathrm{ml}$, and washed with frequent changes for $16-20 \mathrm{~h}$ at $37^{\circ} \mathrm{C}$. A PCA positive cell was identified by the formation of microscopically visible strands of fibrin surrounding the cell. Monocytes were identified by the presence of nonspecific esterase red reaction product and lymphocytes by morphology and the absence of nonspecific esterase. 300 cells were counted per slide, and the results were expressed as percent positive for PCA for each cell type.

\section{RESULTS}

Lipoprotein-induced PCA. Isolated human plasma lipoproteins possessed differing capacities to induce 
TABLE I

PCA of Cell Subpopulations following Lipoprotein Stimulation of PBM

\begin{tabular}{lccc}
\hline \multicolumn{1}{c}{ Stimulus } & \multicolumn{3}{c}{ Total cellular PCA } \\
\hline Lipoprotein & $\mu g$ protein/ml & $m U / 10^{6}$ lymphocytes & $m$ mU/10 monocytes \\
$\quad$ buffer & - & $48 \pm 10$ & $2,850 \pm 550$ \\
VLDL & 36 & $50 \pm 8$ & $10,450 \pm 500$ \\
IDL & 149 & $64 \pm 10$ & $26,500 \pm 1,500$ \\
LDL & 481 & $43 \pm 6$ & $1,650 \pm 400$ \\
HDL & 273 & $35 \pm 8$ & $21,500 \pm 450$ \\
\hline
\end{tabular}

$1 \times 10^{6} \mathrm{PBM}$ were incubated at $37^{\circ} \mathrm{C}$ in $5 \% \mathrm{CO}_{2}$ in $10 \%$ fetal calf serum fortified RPMI-1640 for $48 \mathrm{~h}$, washed, and incubated with either the lipoproteins or buffer for $6 \mathrm{~h}$ at $37^{\circ} \mathrm{C}$. Separated lymphocytes ( $2 \%$ esterase positive) and monocytes (98\% esterase positive) were assayed separately for total PCA content.

PCA when they were incubated for $6 \mathrm{~h}$ or more with human PBM. As illustrated in the preceding study, a representative preparation of VLDL induced little, if any, increase of PCA expression at concentrations $<1.5 \mu \mathrm{g}$ protein $/ \mathrm{ml}$, but at $80 \mu \mathrm{g} / \mathrm{ml}$ induced a maximal increase of 6.7-fold over basal level. IDL and HDL were active at $2.5-85$ and $30-500 \mu \mathrm{g}$ protein $/ \mathrm{ml}$, respectively, with $>12$-fold maximal increases of PCA. In contrast, LDL at concentrations as high as $1 \mathrm{mg} / \mathrm{ml}$ did not induce PCA.
To localize the cellular source of PCA, PBM were precultured for $48 \mathrm{~h}$ to facilitate adherence, followed by a further 6-h incubation with the lipoproteins. The adherent and nonadherent cell populations were then separated and assayed for total PCA content. An increase in PCA above basal levels was observed only in the adherent or monocyte population of the VLDL-, IDL-, or HDL-exposed PBM cultures (Table I). These cells were $98 \%$ positive for nonspecific esterase, a monocyte marker. The lymphocyte PCA did not increase, and represented $<4 \%$ of the total PCA of the original lymphocyte-monocyte mixture. The increase of PCA could all be accounted for in the monocyte population derived from the PBM; and it was concluded that the monocyte or a specifically coisolated adherent cell appeared to be the source of the VLDL-, IDL-, and HDL-induced PCA.

The presence of PCA in individual cells was analyzed more critically by a cytologic plaque assay. Individual cells were identified microscopically as monocytes by the presence of the red cytoplasmic reaction product of nonspecific esterase following culture, and positive for PCA as evidenced by the presence of encircling fibrin strands (Fig. 1). In control PBM cultures, $14 \%$ of the monocytes and $2 \%$ of the lymphocytes contained detectable PCA (Table II). Incubation with LPS, IDL, and HDL increased the number of PCA positive monocytes to $>80 \%$, with no apparent increase in the small proportion of PCA positive esterase nega-
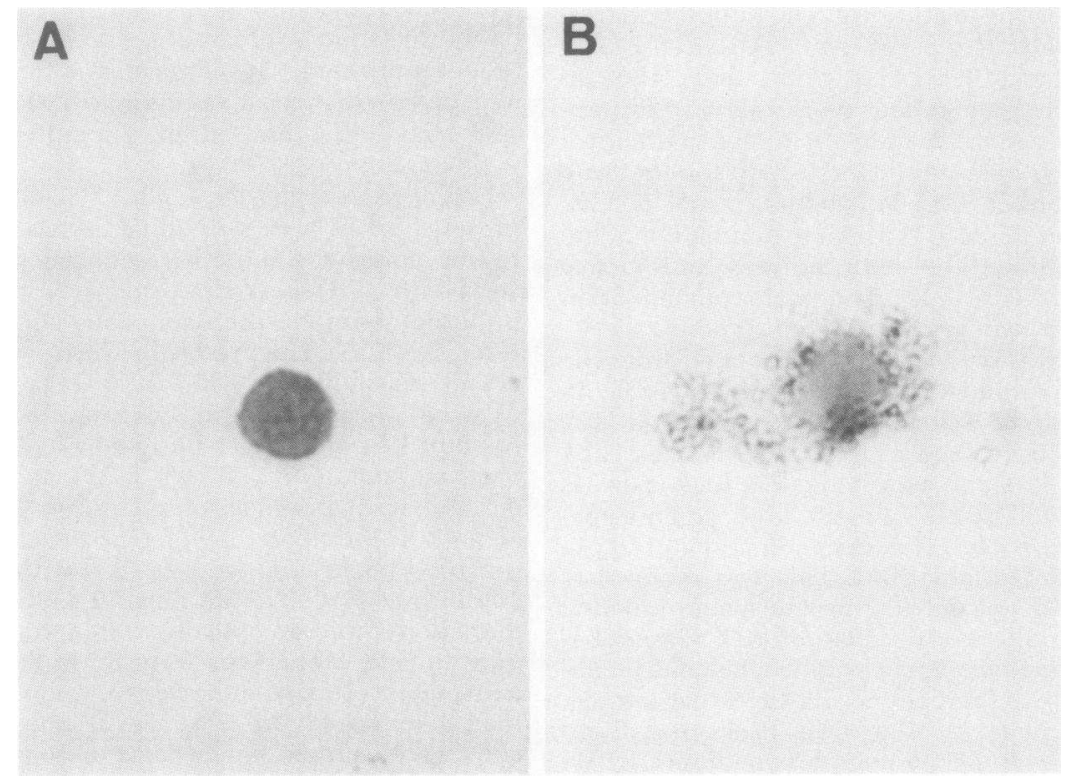

FIGURE 1 Plaque assay for demonstration of PCA in individual cells. Panel A contains a fixed esterase positive cell that was cultured for $6 \mathrm{~h}$ in the presence of the lipoprotein buffer control. Panel B contains a fixed esterase positive cell which is also positive for PCA expression as evidenced by the encircling fibrin strands. Note that the red esterase reaction cannot be differentiated in the black and white photograph. 
TABLE II

Cytologic Analysis of Cellular PCA

\begin{tabular}{lcc}
\hline & \multicolumn{2}{c}{ PCA positive cells } \\
\cline { 2 - 3 } Stimulus & $\begin{array}{c}\text { Esterase negative } \\
\text { (lymphocytes) }\end{array}$ & $\begin{array}{c}\text { Esterase positive } \\
\text { (monocytes) }\end{array}$ \\
\hline Lipoprotein & & $\%$ \\
buffer & 2 & \\
LPS & 5 & 14 \\
VLDL & 6 & 86 \\
IDL & 8 & 44 \\
LDL & 4 & 82 \\
HDL & 5 & 21 \\
\end{tabular}

$1 \times 10^{6}$ PBM were cultured with $197,500,929$, and $732 \mu \mathrm{g}$ protein/ml of VLDL, IDL, LDL, or HDL, respectively, for $6 \mathrm{~h}$, and then air dried onto glass slides. The cells were overlaid with a solution containing agarose, citrated plasma, and $\mathrm{CaCl}_{2}$, and incubated for an additional $10 \mathrm{~min}$ at $37^{\circ} \mathrm{C}$. The slides were washed with heparin-saline overnight, and stained with nonspecific esterase. 300 cells were counted for the presence of fibrin strands encircling them (PCA positive).

tive cells which were also cytologically consistent with lymphocytes. In contrast, only $44 \%$ of the monocytes and few lymphocytes were PCA positive after incubation with VLDL, and this fraction could not be further increased. It was noted that there was a modest increase in PCA positive monocytes following exposure of PBM to LDL (Table II), though there was a mild decrease in total monocyte PCA content by quantitative assay (Table I), suggesting that the mean PCA content per cell must be lower.

When isolated monocytes or lymphocytes were separately incubated at $37^{\circ} \mathrm{C}$ for $6 \mathrm{~h}$ with each of the lipoproteins, there was no increase in PCA above the basal level (Table III). Thus, a collaboration between both cell populations appeared to be required for lipoprotein-stimulated amplification of monocyte PCA, since neither cell population alone could be stimulated directly to express increased levels of PCA.

TABLE III

Failure of Direct Monocyte or Lymphocyte Amplification of PCA by Incubation with Lipoproteins

\begin{tabular}{lccc}
\hline \multicolumn{1}{c}{ Stimulus } & \multicolumn{2}{c}{ Total cellular PCA content } \\
\hline Mg protein/ml & $\begin{array}{c}\text { mU/10 } \\
\text { lymphocytes* }\end{array}$ & $\begin{array}{c}\text { mU/10 } \\
\text { monocytes }\end{array}$ \\
$\begin{array}{l}\text { Lipoprotein } \\
\text { buffer }\end{array}$ & - & $42 \pm 9$ & $3,150 \pm 210$ \\
VLDL & 36 & $41 \pm 4$ & $4,150 \pm 575$ \\
IDL & 149 & $37 \pm 6$ & $3,745 \pm 355$ \\
LDL & 481 & $43 \pm 5$ & $3,550 \pm 510$ \\
HDL & 273 & $34 \pm 8$ & $2,940 \pm 200$ \\
\hline
\end{tabular}

* Less than $2 \%$ nonspecific esterase positive.

\$ Greater than $98 \%$ nonspecific esterase positive.
Lymphocyte requirement for generation of macrophage PCA. To verify the apparent requirement for cellular collaboration for the amplification of monocyte PCA, isolated lymphocytes, freed of monocytes by adherence, were incubated for $6 \mathrm{~h}$ with each of the lipoprotein classes. Then, either the washed lipoprotein-stimulated lymphocytes or medium from the lipoprotein-stimulated lymphocytes were incubated for another $6 \mathrm{~h}$ with isolated monocytes. Only monocytes incubated with intact lymphocytes which had been incubated with VLDL, IDL, or HDL demonstrated an increase in PCA, whereas the addition of control lymphocytes or those exposed to LDL had no effect on monocyte PCA (Table IV). Similarly, when isolated monocytes were incubated with each of the lipoproteins, washed free of non-cell-associated lipoproteins and then added to lymphocytes, no increase in PCA was observed in either the lymphocytes or the monocytes (data not shown). This indicated a undirectional collaboration between the lymphocyte and the monocyte.

This lymphocyte interaction with monocytes required intact lymphocytes, since neither the medium from those cells (Table IV) nor homogenates of lipoprotein-stimulated lymphocytes substituted for viable lipoprotein-stimulated lymphocytes (data not shown). It was concluded that the VLDL-, IDL-, and HDL-induced increase in monocyte PCA required the presence of the intact lymphocyte. A closer examination of the PCA obtained from monocytes exposed to LDL lymphocyte culture supernates (Table IV), suggested that culture supernates containing LDL may inhibit the basal level of monocyte PCA; however, this was not statistically significant.

The optimal lymphocyte-to-monocyte ratio for PCA induction was examined by adding increasing numbers of viable lymphocytes to a constant number of mono-

TABLE IV

Amplification of Monocyte PCA by Incubation with Lipoprotein-stimulated Lymphocytes

\begin{tabular}{|c|c|c|c|}
\hline \multicolumn{2}{|c|}{ Lymphocyte culture* } & \multicolumn{2}{|c|}{ Monocyte induction } \\
\hline Stimulus & & Culture medium & Lymphocytes \\
\hline & $\mu \mathrm{g}$ protein/ml & \multicolumn{2}{|c|}{ mU PCA $/ 10^{\circ}$ monocytes } \\
\hline Lipoprotein & & & \\
\hline buffer & 一 & $2,300 \pm 500$ & $1,950 \pm 400$ \\
\hline VLDL & 36 & $2,650 \pm 600$ & $12,550 \pm 400$ \\
\hline IDL & 149 & $3,500 \pm 1,000$ & $31,500 \pm 1,200$ \\
\hline LDL & 481 & $1,850 \pm 400$ & $1,450 \pm 250$ \\
\hline HDL & 273 & $2,450 \pm 600$ & $28,500 \pm 1,400$ \\
\hline
\end{tabular}

$* 8.5 \times 10^{5}$ lymphocytes in $1 \mathrm{ml}$ complete medium for $6 \mathrm{~h}$ at $37^{\circ} \mathrm{C}$.

$\$ 1 \times 10^{5}$ monocytes were cultured for $6 \mathrm{~h}$ with the culture medium from the lymphocytes, or with $8.5 \times 10^{5}$ viable washed lymphocytes that had been exposed to the lipoproteins. 
cytes, followed by addition of the lipoproteins. Although the induced level of PCA differed for different lipoprotein stimuli, an increase in the PCA content was observed for all stimulatory lipoproteins at lymphocyteto-monocyte ratios $>2: 1$ and maximal PCA was observed at lymphocyte-to-monocyte ratios >5:1 (Fig. 2).

The temperature dependence of the lipoproteinlymphocyte interaction for induction of PCA was examined in an indirect two-stage assay. In the first stage, $8 \times 10^{5}$ lymphocytes were incubated with each of the lipoproteins for $30 \mathrm{~min}$ at either $37^{\circ}$ or $4^{\circ} \mathrm{C}$ and then washed twice at the same temperature. In the second stage, the lymphocytes were incubated with $1.2 \times 10^{5}$ adherent monocytes for $6 \mathrm{~h}$ at $37^{\circ} \mathrm{C}$. Following removal of the lymphocytes, the monocytes were assayed for PCA content. VLDL, IDL, and HDL were equally effective lymphocyte activators at either $4^{\circ}$ or $37^{\circ} \mathrm{C}$ (Fig. 3 ), indicating that the interaction of the stimulatory lipoproteins with the lymphocytes was not temperature dependent. This was in contrast to the observation that lymphocytes exposed to LPS at $4^{\circ} \mathrm{C}$ were unable to collaborate with monocytes in the generation of increased PCA. This suggested a difference in the nature of the lymphocyte interaction with the stimulatory lipoproteins as contrasted with LPS.

In addition, we investigated the potential role of platelets in the induction of monocyte PCA. Platelets were present in the isolated PBM at 35-40 platelets per mononuclear cell, and after $72 \mathrm{~h}$ of culture the isolated lymphocyte preparations contained $\sim 4$ platelets per lymphocyte. The possibility that platelets exposed to these lipoproteins contributed to the induction of monocyte PCA was examined by first depleting the blood of platelets before isolation of the PBM. After 72

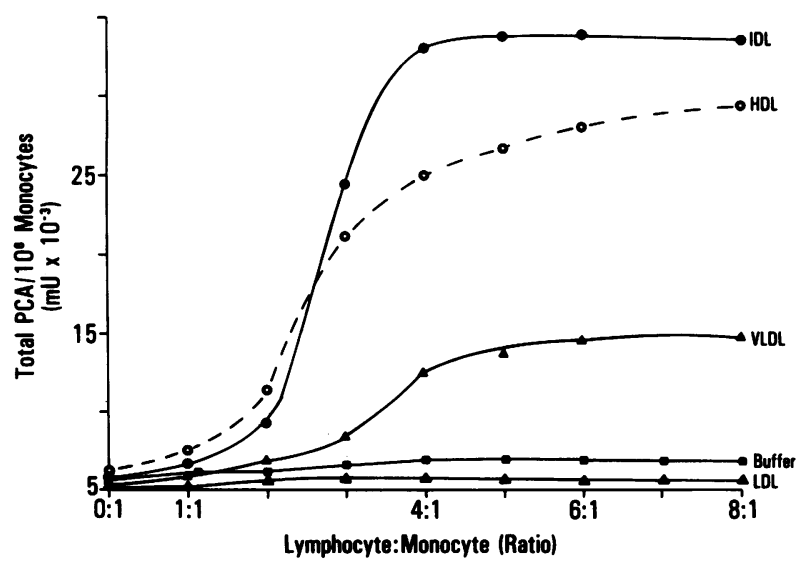

FIGURE 2 Requirement for lipoprotein-triggered lymphocytes. Increasing numbers of lymphocytes $\left(1-8 \times 10^{5}\right)$ were added to $1 \times 10^{5}$ monocytes in $1-\mathrm{ml}$ cultures. VLDL, IDL, LDL, and HDL were added at 180,740, 2,405, and 1,360 $\mu \mathrm{g}$ protein $/ \mathrm{ml}$, respectively, and the cells cultured for $6 \mathrm{~h}$ at $37^{\circ} \mathrm{C}$. The washed monocytes were assayed for total PCA content as described.

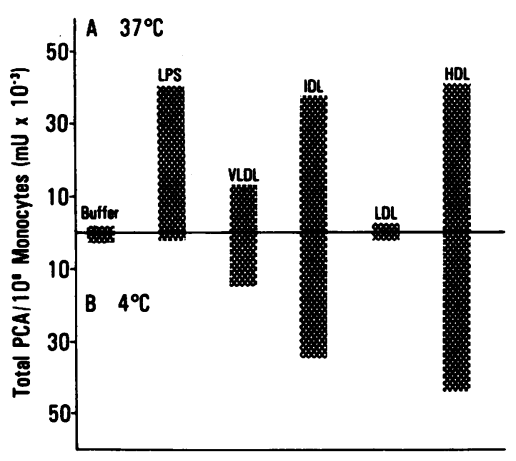

Figure 3 Effect of temperature on the triggering capability of lymphocytes by lipoproteins or LPS. $8.5 \times 10^{5}$ lymphocytes were cultured in complete medium at either $37^{\circ} \mathrm{C}$ (panel A) or $4^{\circ} \mathrm{C}$ (panel B) with either buffer or LPS, or VLDL, IDL, LDL, and HDL at $190,748,1,740$, and $1,975 \mu$ g protein $/ \mathrm{ml}$, respectively, for $30 \mathrm{~min}$. The lymphocytes were then washed and added to $1.2 \times 10^{5}$ monocytes for an additional $6 \mathrm{~h}$ of culture at $37^{\circ} \mathrm{C}$ before assay of the total monocyte PCA content.

$\mathrm{h}$ of culture, the lymphocyte preparations contained $<0.2$ platelets per lymphocyte. These lymphocytes were then incubated at $37^{\circ} \mathrm{C}$ for $30 \mathrm{~min}$ with each of the lipoproteins in the presence or absence of freshly isolated platelets from the same individual. In the second stage, the washed lymphocytes and/or platelets were incubated with $1 \times 10^{5}$ adherent monocytes for $6 \mathrm{~h}$ at $37^{\circ} \mathrm{C}$. Following removal of the lymphocytes and/or platelets, the monocytes were assayed for PCA content (Table V). Platelets did not substitute for lymphocytes, nor did they interfere with the lymphocyte requirement for LPS-, VLDL-, IDL-, or HDL-triggered induction of monocyte PCA.

TABLE V

Platelets Will Not Replace the Lymphocyte Requirement for Monocyte PCA Expression

\begin{tabular}{|c|c|c|c|c|}
\hline \multicolumn{2}{|c|}{$\begin{array}{l}\text { Lymphocyte/ } \\
\text { platelet cultures }\end{array}$} & \multicolumn{3}{|c|}{ Monocytes incubated with* } \\
\hline & & & & Lymphocytes \\
\hline \multirow{2}{*}{ Stimulus } & & Lymphocytest & Platelets§ & and platelets" \\
\hline & $\mu \mathrm{g} / \mathrm{ml}$ & \multicolumn{3}{|c|}{$\mathrm{mU} \mathrm{PCA} / 10^{6}$ monocytes } \\
\hline LLB & 一 & $3,400 \pm 0$ & $1,950 \pm 490$ & $3,150 \pm 640$ \\
\hline LPS & 10 & $26,500 \pm 4,240$ & $2,880 \pm 600$ & $22,750 \pm 1,160$ \\
\hline VLDL & 50 & $14,750 \pm 4,600$ & $1,650 \pm 490$ & $18,500 \pm 2,210$ \\
\hline IDL & 50 & $29,500 \pm 3,540$ & $2,150 \pm 640$ & $36,000 \pm 8,490$ \\
\hline LDL & 200 & $1,500 \pm 420$ & $2,280 \pm 320$ & $2,230 \pm 1,100$ \\
\hline HDL & 500 & $24,500 \pm 710$ & $2,500 \pm 710$ & $22,000 \pm 8,490$ \\
\hline
\end{tabular}

$* 1 \times 10^{5}$ monocytes (98\% esterase positive) containing $<1$ platelet/monocyte were incubated with lymphocytes and/or platelets for $6 \mathrm{~h}$ at $37^{\circ} \mathrm{C}$ and the reisolated monocytes were assayed for total PCA content.

$\$ 8 \times 10^{5}$ lymphocytes ( $2 \%$ esterase positive) containing $<0.2$ platelets/lymphocyte.

$\$ 2 \times 10^{7}$ platelets.

" $8 \times 10^{5}$ lymphocytes plus $2 \times 10^{7}$ platelets. 
LDL inhibition of PCA expression. The cellular nature of the LDL-mediated inhibitory activity was also examined using indirect two-stage assays. In the first stage, the isolated lymphocytes were incubated with maximal stimulatory concentrations of either VLDL, IDL, or $\mathrm{HDL}$ at 50,50 , and $500 \mu \mathrm{g} / \mathrm{ml}$, respectively, either alone or in the presence of LDL for $6 \mathrm{~h}$ at $37^{\circ} \mathrm{C}$. In the second stage, the washed viable lymphocytes or culture medium from the lymphocytes were incubated with $1 \times 10^{5}$ adherent monocytes for an additional $6 \mathrm{~h}$ at $37^{\circ} \mathrm{C}$. Following removal of the lymphocytes, the monocytes were assayed for their PCA content. The presence of $200 \mu \mathrm{g} \mathrm{LDL} / \mathrm{ml}$, a concentration which will inhibit PBM generation of PCA (see preceding manuscript for dose relationships), had no effect on the VLDL, IDL, or HDL stimulation of the lymphocyte, and full expression of monocyte PCA was observed when intact lymphocytes were added (Table VI). Culture media from the lipoprotein-stimulated lymphocytes did not stimulate PCA expression, and this was consistent with the previous observation (Table IV) that only intact lymphocytes that had been exposed to the appropriate lipoproteins could stimulate monocyte PCA expression. However, the amount of PCA obtained by adding the lymphocyte culture medium (data not shown) was in most cases less than basal level (buffer only), suggesting again that the LDL present in this culture medium could act at the level of the monocyte.

To test this directly, lipoprotein- or LPS-stimulated lymphocytes were added to LDL-exposed monocytes using a similar two-stage assay. The first stage involved the incubation at $37^{\circ} \mathrm{C}$ of isolated lymphocytes with 50 ,

TABLE VI

LDL Does Not Inhibit PCA Expression by Suppressing Lymphocyte Function

\begin{tabular}{lccc}
\hline \multicolumn{1}{c}{ Stimulus } & Lymphocyte culture* $^{*}$ & LDL & Total monocyte PCA \\
\hline $\begin{array}{l}\text { Lipoprotein } \\
\quad \text { buffer }\end{array}$ & $\mu g / m l$ & $\mu g / m l$ & $m U / 10^{6}$ cells \\
Lipoprotein & - & - & $3,375 \pm 75$ \\
$\quad$ buffer & - & 200 & $2,650 \pm 250$ \\
VLDL & 50 & - & $19,250 \pm 1,750$ \\
VLDL & 50 & 200 & $13,000 \pm 2,000$ \\
IDL & 50 & - & $20,000 \pm 3,000$ \\
IDL & 50 & 200 & $19,250 \pm 2,750$ \\
HDL & 500 & - & $17,000 \pm 3,000$ \\
HDL & 500 & 200 & $18,000 \pm 1,000$ \\
\hline
\end{tabular}

$* 8.5 \times 10^{5}$ viable lymphocytes were incubated in $1 \mathrm{ml}$ of complete medium for $6 \mathrm{~h}$, washed, and placed in fresh medium before addition to the monocytes. No loss of lymphocyte viability was observed during the culture period.

$\$ 1 \times 10^{5}$ monocytes in $1 \mathrm{ml}$ cultured for $6 \mathrm{~h}$ with $8.5 \times 10^{5}$ lymphocytes. The monocytes were recovered for assay of total PCA.
50,500 , and $10 \mu \mathrm{g} / \mathrm{ml}$ of VLDL, IDL, HDL, or LPS, respectively. At the same time, $1 \times 10^{5}$ isolated monocytes were incubated at $37^{\circ} \mathrm{C}$ with $200 \mu \mathrm{g} / \mathrm{ml} \mathrm{LDL}$. After $6 \mathrm{~h}$, both the lymphocyte and the monocyte cultures were washed free of non-cell-associated lipoproteins, the cell viability was assessed, and during the second stage the cultures were cultured together for an additional $6 \mathrm{~h}$ at $37^{\circ} \mathrm{C}$ for generation of monocyte PCA. Greater than $78 \%$ suppression of both lipoprotein and LPS amplification of PCA was observed (Table VII), even though the monocytes were fully viable by reference to dye exclusion. The lack of cytotoxicity was further indicated by the lack of effect of LDL on lymphocytes that were triggered with the other classes of lipoproteins (Table VI). It was concluded that LDL is active in this system by suppressing monocyte expression rather than by inhibiting lymphocyte stimulation of cellular PCA induction.

\section{DISCUSSION}

The present studies define a new in vitro regulatory network in which the synthesis of procoagulant molecules by monocytes can be induced by certain plasma lipoproteins via the lymphocyte, and directly suppressed by another. The complexity of this system is suggested by the observation that the PBM are recovered from blood where they are exposed to these

TABLE VII

LDL Inhibits PCA Expression by Directly Suppressing Monocyte Function

\begin{tabular}{|c|c|c|c|}
\hline \multicolumn{2}{|c|}{ Lymphocytes* } & \multirow{2}{*}{$\begin{array}{c}\text { Monocytes } \\
\text { LDL }\end{array}$} & \multirow[b]{2}{*}{ Total monocyte PCA } \\
\hline Stimulus & & & \\
\hline & $\mu g / m l$ & $\mu g / m l$ & $m U / 10^{6}$ cells monocytes \\
\hline Lipoprotein & & & \\
\hline buffer & - & - & $2,630 \pm 250$ \\
\hline Lipoprotein & & & \\
\hline buffer & 一 & 200 & $1,850 \pm 70$ \\
\hline LPS & 10 & - & $25,750 \pm 3,890$ \\
\hline LPS & 10 & 200 & $5,500 \pm 990$ \\
\hline VLDL & 50 & - & $15,250 \pm 1,060$ \\
\hline VLDL & 50 & 200 & $3,150 \pm 350$ \\
\hline IDL & 50 & - & $22,750 \pm 1,770$ \\
\hline IDL & 50 & 200 & $2,350 \pm 640$ \\
\hline HDL & 500 & - & $29,750 \pm 177$ \\
\hline HDL & 500 & 200 & $4,500 \pm 1,420$ \\
\hline
\end{tabular}

* $8.5 \times 10^{5}$ isolated lymphocytes were cultured in $1 \mathrm{ml}$ for $6 \mathrm{~h}$ at $37^{\circ} \mathrm{C}$ with LPS or stimulatory lipoproteins and washed before addition to the monocyte cultures.

$\$ 1 \times 10^{5}$ isolated monocytes were incubated at $37^{\circ} \mathrm{C}$ for $6 \mathrm{~h}$ in the presence or absence of LDL, washed, and then cultured with LPS or lipoprotein-stimulated lymphocytes for an additional $6 \mathrm{~h}$ at $37^{\circ} \mathrm{C}$. Monocytes were reisolated before assay of total PCA. No loss of monocyte viability was detected by culture in the presence of LDL. 
lipoproteins. Yet, they appear to be in a basal or latent state since they respond to new lipoprotein exposure and initiate the reaction in vitro. We have demonstrated in the preceding study that not only is there an increase in the total cellular content of PCA, but that $\sim 14 \%$ of the total cellular activity is expressed by viable cells following a 6-h incubation with either VLDL, IDL, or HDL, suggesting that the biologically responsible molecules are secreted or exposed on the surface of viable cells. In this study, the cellular pathways for this phenomenon were examined. Lipoprotein stimulation of PBM followed by separate assay of the lymphocyte and monocyte populations indicated that the monocyte was the source of virtually all the induced PCA. Lymphocyte PCA, though detectable, was $<2 \%$ of the basal monocyte PCA and $<0.2 \%$ of the IDL- and HDL-induced monocyte PCA. Cytologic examination of individual cells in the plaque assay unequivocally identified the monocyte, i.e., nonspecific esterase positive cell, as the major source of both basal and induced PCA. In no instance were $>8 \%$ of the esterase negative cells positive for PCA, while $14 \%$ of the basal and up to $93 \%$ of the stimulated esterase positive cells generated PCA. The majority of monocytes expressed this activity, and thus it was not the product of a minor cellular subpopulation of adherent cells.

With the monocyte identified as the source of the VLDL-, IDL-, and HDL-induced PCA, we investigated further whether the monocyte was autonomous with respect to this function. Direct lipoprotein stimulation of isolated monocytes resulted in no increase of PCA, whereas in the presence of lymphocytes, cellular PCA was increased. The requirement for lymphocyte participation was directly indicated by incubating lymphocytes with the stimulatory lipoproteins, adding the washed lymphocytes to isolated monocytes, and observing full expression of monocyte PCA. Platelets, the major contaminant of the lymphocyte preparations, could not substitute for lymphocytes nor did they appear to influence the lymphocyte induction of monocyte PCA. A minimum ratio of lymphocytes to monocytes of $2: 1$ was required, whereas maximum induction occurred at ratios $>5: 1$. The collaboration seemed to require direct contact by intact cells since neither the culture medium from, nor the cell homogenates of VLDL-, IDL-, and HDL-stimulated lymphocytes were effective.

The ability of various classes of plasma lipoproteins to interact with peripheral blood lymphocytes has been reported. Ho et al. (14) have described the existence of a high affinity receptor on normal human lymphocytes which binds LDL but not HDL, and is involved in regulating the intracellular supply of cholesterol. However, this high affinity receptor for LDL is not fully expressed on freshly isolated lymphocytes (13). Curtiss and Edgington (15) have demonstrated that lymphocytes also possess a saturable surface receptor for a specific minor subset of plasma lipoproteins contained with the IDL fraction, termed LDL-In. This immunoregulatory lymphocyte receptor, which is distinct from the LDL receptor, also does not bind human HDL and requires preculture of the lymphocytes in lipoprotein-deficient serum for full expression. High affinity VLDL and/or HDL binding to lymphocytes has not been established, although some studies have indicated that HDL and VLDL interact with various cell surfaces $(16,17)$. The relationship of these previously described plasma lipoprotein interactions with lymphocytes to those described in this study is as yet unknown. The temperature requirements for the interaction of the stimulatory plasma lipoproteins with the lymphocyte indicated that freshly isolated lymphocytes were fully functional in this system after only a $30-\mathrm{min}$ exposure at $4^{\circ} \mathrm{C}$. This suggests that these lipoproteins need only interact with the lymphocyte for a short period of time, and that the lipoprotein-initiated signal for triggering lymphocytes is both rapid and independent of temperature.

In striking contrast to the VLDL, IDL, and HDL stimulatory lipoproteins, LDL did not induce monocyte PCA when it was incubated with either PBM, platelets, isolated lymphocytes or isolated monocytes. Instead, LDL was capable of actively suppressing the cellular PCA induced by the other lipoprotein classes. This suppression could be accomplished with molar ratios of LDL-to-stimulatory lipoproteins of $1: 3$ or less, and suggested that LDL was not active in this in vitro system by interacting either directly with the stimulatory lipoproteins, or with the stimulated lymphocyte. This interpretation was further supported by the fact that the monocyte appeared to be the only site of LDLmediated suppression. Viable lymphocytes exposed to either VLDL, IDL, or HDL in the presence of LDL were viable and fully functional when they were washed and added to monocytes. Only exposure of monocytes to LDL resulted in suppression of PCA amplification. This LDL-mediated suppression of monocyte function was not the result of a cytotoxic reaction and did not require the continued presence of non-cell-associated LDL during either monocyte activation by the stimulated lymphocyte or the subsequent 6-h culture period for full PCA expression.

Macrophages are capable of taking up and degrading modified LDL (18), and it has been reported that human PBM possess receptors for both native and modified LDL (19). Inhibition of one type of macrophage effector function by LDL has been reported. Chapman and Hibbs (20) have demonstrated that plasma LDL, but not HDL inhibits the tumoricidal capability of activated peritoneal macrophages. Yamazaki et al. (21) have also shown that LDL, but not HDL isolated from cell-free ascites fluids can inhibit macro- 
phage-mediated cytolysis. A suppressive activity of normal mouse serum identified by its ability to inhibit a primary in vitro plaque-forming cell response has been described (22). This inhibitory activity acts directly on the adherent cell, and it, too, may be eventually identified as a serum LDL.

Although the mechanistic details of LDL suppression of monocyte PCA synthesis following exposure to lipoprotein-stimulated lymphocytes are not yet known, suppression is general in that LPS-triggered lymphocytes were also unable to stimulate LDL-suppressed monocytes to generate PCA (Table VII). Thus, LDL inhibition of selected pathways of monocyte activation or differentiation other than those described here may be a general phenomenon. If heightened macrophage cytolytic activity and the amplification of monocyte PCA share common or parallel pathways of macrophage or monocyte activation, then the studies of Chapman and Hibbs (20) may suggest a possible mechanism for the LDL-mediated inhibition we have described. In their studies, the inhibitory activity of LDL for macrophage tumor cell lysis could be mimicked by temporarily increasing the cholesterol content of the macrophage plasma membrane by incubating the macrophages with cholesterol-phospholipid liposomes. These studies imply that the neutral lipid content, especially the free cholesterol content of LDL, may be the biologically active constituent. Changes in membrane fluidity resulting from transfer of free cholesterol from LDL to the monocyte membrane could possibly account for functional inhibition of

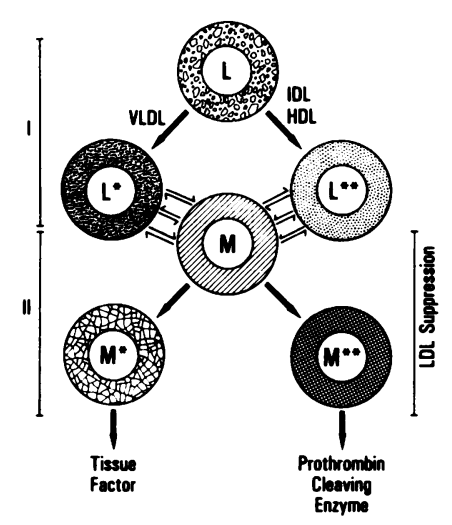

Figure 4 A two-phased diagramatic representation of the observed cellular events of plasma lipoprotein induction and suppression of cellular PCA expression. In the first phase, lymphocytes $(\mathrm{L})$ are exposed to a lipoprotein stimulus. In the second phase, monocyte PCA is generated. Monocytes stimulated by VLDL-triggered lymphocytes $\left(\mathrm{L}^{*}\right)$ express tissue thromboplastin or tissue factor $\left(\mathbf{M}^{*}\right)$, whereas monocytes exposed to IDL- or HDL-triggered lymphocytes $\left(\mathrm{L}^{* *}\right)$ express a direct prothrombinase activity $\left(\mathbf{M}^{* *}\right)$. LDL directly inhibits the expression of both types of monocyte PCA, yet has no effect on lymphocyte triggering. monocyte PCA expression, but this will require direct analysis.

In this and the accompanying report we have described a series of cellular events involving two circulating cell types and four classes of circulating plasma constituents, which can regulate the in vitro induction and suppression of two types of PCA. This complex network of cellular events has been summarized in Fig. 4. Since all the components of this in vitro system circulate together in vivo, it would appear that these events might occur in vivo; however, both lymphocytes and monocytes as isolated are in a latent or uninduced state. The influence of other plasma proteins, recovery periods following exposure, as well as other influences on the latency of this regulatory network might explain this apparent dichotomy. A number of such issues must be resolved in order to understand these apparent differences between the lack of induction of lymphocytes in vivo by exposure to the stimulatory lipoproteins and their rapid recovery in vitro. The complete elucidation of this cellular pathway promises to provide new perspective perhaps not only in the genesis of thrombotic diseases, but also in regard to the complex regulatory and functional roles of cells of the reticuloendothelial system.

\section{ACKNOWLEDGMENTS}

We wish to thank Shu-Lan Cheng, D. J. Bonnet, and Mary Ellen Pizzolato for their excellent technical help, and Sandy Thompson for preparation of the manuscript.

This work was supported by National Institutes of Health grants CA 14346, CA 28116, HL 16411, AI 14921, training grant HL 07195, and a fellowship from the Medical Research Council of Canada.

\section{REFERENCES}

1. Rothberger, H., T. S. Zimmerman, H. L. Spiegelberg, and J. H. Vaughan. 1977. Leukocyte procoagulant activity. Enhancement of production in vitro by IgG and antigen-antibody complexes. J. Clin. Invest. 59: 549-557.

2. Rothberger, H., T. S. Zimmerman, and J. H. Vaughan. 1978. Increased production and expression of tissue thromboplastin-like procoagulant activity in vitro by allogeneically stimulated human leukocytes. J. Clin. Invest. 62: 649-655.

3. Wadell, J., W. L. Johnson, J. G. Pool, and W. P. Creger. 1966. Thromboplastic activity in cultured blood leukocytes. Clin. Res. 14: 169A. (Abstr.)

4. Craig, S. K., and J. Niemetz. 1973. Tissue factor activity of normal and leukemic cells. Blood. 42: 729-735.

5. Rickles, F. R., J. Levin, J. A. Hardin, C. F. Barr, and M. F. Conrad, Jr. 1977. Tissue factor generation by human mononuclear cells: effects of endotoxin and dissociation of tissue factor generation from mitogenic response. $J$. Lab. Clin. Med. 89: 792-803.

6. Muhlfelder, T. W., J. Niemetz, D. Kreutzer, D. Beebe, P. A. Ward, and S. I. Rosenfeld. 1979. C5 chemofactor fragment induces leukocyte production of tissue factor activity, a link between complement and coagulation. $J$. Clin. Invest. 63: 147-150.

7. Levy, G. A., and T. S. Edgington. 1980. Lymphocyte co- 
operation is required for amplification of macrophage procoagulant activity. J. Exp. Med. 151: 1232-1244.

8. Edwards, R. L., and R. F. Rickles. 1980. The role of human $\mathrm{T}$ cells (and $\mathrm{T}$ cell products) for monocyte tissue factor generation. J. Immunol. 125: 606-609.

9. Markwell, M. A. K., S. M. Haas, L. L. Bieber, and N. E. Tolbert. 1978. A modification of the Lowry procedure to simplify protein determination in membrane and lipoprotein samples. Anal. Biochem. 87: 206-210.

10. Levin, J., P. A. Tomasulo, and R. S. Oser. 1970. Detection of endotoxin in human blood and demonstration of an inhibitor. J. Lab. Clin. Med. 75: 903-911.

11. Morrison, D. C., J. A. Louis, and W. O. Weigle. 1976. Dissociation of anticomplementary and adjuvant properties of protein derived from cobra venom. Immunology. 30: 317-323.

12. Boyum, A. 1976. Isolation of lymphocytes, granulocytes and macrophages. Scand. J. Immunol. Suppl. 5: 5-15.

13. Li, C. Y., K. W. Lam, and L. T. Yam. 1973. Esterases in human leukocytes. J. Histochem. Cytochem. 21: 1-12

14. Ho, Y. K., M. S. Brown, D. W. Bilheimer, and J. L. Goldstein. 1976. Regulation of low density lipoprotein receptor activity in freshly isolated human lymphocytes. J. Clin. Invest. 58: 1465-1474.

15. Curtiss, L. K., and T. S. Edgington. 1978. Identification of a lymphocyte surface receptor for low density lipoprotein inhibitor, an immunoregulatory species of normal human serum low density lipoprotein. J. Clin. Invest. 61: 1298-1308.

16. Brown, M. S., and J. L. Goldstein. 1974. Familial hyper- cholesterolemia: defective binding of lipoproteins to culture fibroblasts associated with impaired regulation of 3-hydroxy-3-methylglutaryl coenzyme A reductase activity. Proc. Natl. Acad. Sci. U. S. A. 71: 788-792.

17. Stein, O., and Y. Stein. 1976. Surface binding and internalization of homologous and heterologous serum lipoproteins by rat aortic smooth muscle cells in culture. Biochim. Biophys. Acta. 431: 363-368.

18. Goldstein, J. L., Y. K. Ho, M. S. Brown, T. L. Innerarity, and R. W. Mahley. 1980. Cholesterol ester accumulation in macrophages resulting from receptor-mediated uptake and degradation of hypercholesterolemic canine betavery low density lipoproteins. J. Biol. Chem. 255: 18391848.

19. Traber, M. G., and H. J. Kayden. 1980. Low density lipoprotein receptor activity in human monocyte-derived macrophages and its relation to atheromatous lesions. Proc. Natl. Acad. Sci. U. S. A. 77: 5466-5470.

20. Chapman, H. A., and J. B. Hibbs, Jr. 1977. Modulation of macrophage tumoricidal capability by components of normal serum: a central role for lipid. Science (Wash. D. C.). 197: 282-285.

21. Yamazaki, M., H. Shinoda, R. Hattori, and D. Mizuno. 1977. Inhibition of macrophage-mediated cytolysis by lipoproteins from cell free tumorous ascites. Gann. 68: 513-516.

22. Martineau, R. S., and J. S. Johnson. 1978. Normal mouse serum immunosuppressive activity: action on adherent cells. J. Immunol. 120: 1550-1553. 